\title{
Base Unit of International System of Units
}

National Cancer Institute

\section{Source}

National Cancer Institute. Base Unit of International System of Units. NCI Thesaurus.

Code C42533.

The base units are a choice of seven well-defined units within the International System of Units (Systeme International d'Unites, SI), which by convention are regarded as dimensionally independent and therefore defined in an absolute way without referring to any other units: the meter, the kilogram, the second, the ampere, the kelvin, the mole, and the candela. The base units are consistent with the part of the metric system called the MKS system. 